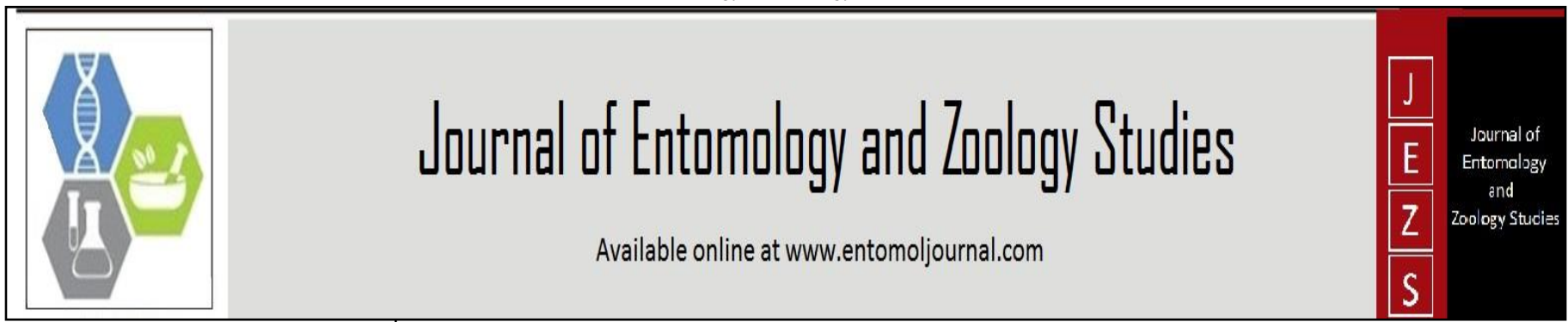

E-ISSN: 2320-7078

P-ISSN: 2349-6800

www.entomoljournal.com

JEZS 2021; 9(5): 281-284

(C) 2021 JEZS

Received: 01-07-2021

Accepted: 03-08-2021

Rituparna De

Medicinal Plants Research \&

Extension Centre, Ramakrishna

Mission, Narendrapur, Kolkata,

West Bengal, India

Salil K Gupta

Medicinal Plants Research \&

Extension Centre, Ramakrishna

Mission, Narendrapur, Kolkata,

West Bengal, India
Corresponding Author:

Salil K Gupta

Medicinal Plants Research \&

Extension Centre, Ramakrishna

Mission, Narendrapur, Kolkata,

West Bengal, India

\section{Life cycle of Tetranychus hypogeae Gupta infesting rose in 24 Paraganas district of West Bengal with bio-efficacy of some green pesticides for its management}

\section{Rituparna De and Salil K Gupta}

DOI: https://doi.org/10.22271/j.ento.2021.v9.i5d.8836

\section{Abstract}

The present communication reports the occurrence of a serious mite pest, Tetranychus hypogeae on Blood Beauty and Tajmahal varieties of rose at Horticulture garden of Ramkrishna Mission, Narendrapur during summer season of 2021. The study on its life cycle under laboratory condition revels that it took $11.20 \pm 1.15$ days, fecundity as $34.00 \pm 1.15$ eggs, longevity $(+$ ) as $12.12 \pm 1.15$ days and sex ratio being $1: 3$. The result of the bio-efficacy study with green pesticides indicates that the mean mortality was highest in Parthenium leaf extract $(86.31 \%)$ followed by Lantana camara leaf extract $(82.04 \%)$ and NSKE alcoholic extract (81.68\%), while NSKE aqueous extract was poorest among all registering only $37.86 \%$ mortality. However, all the green pesticides proved having acaricidal effects.

Keywords: Tetranychus hypogeae, life cycle, bio-efficacy, green pesticides, West Bengal

\section{Introduction}

Tetranychus hypogeae which was originally described by Gupta (1976) ${ }^{[4]}$ on groundnut, Arachis hypogea was also recorded on Chrysanthemum sp. (Gupta \& Gupta, 1994) ${ }^{[3]}$. On groundnut, it was found to be attacking seriously but its serious attack on Blood Beauty and Tajmahal varieties of rose have never been reported earlier. Recently, in the summer of 2021, its serious attack on rose plants (Blood Beauty and Tajmahal varieties) at Narendrapur campus of Ramakrishna Mission was observed where 15-20 mites of all stages were seen under surface of leaves causing chlorosis initially, followed by browning, withering and defoliation. Since information about life cycle of this mite was unavailable, an attempt has been made to study the same under laboratory condition. Besides, a laboratory experiment was carried out to study bioefficacy of some green pesticides for management of the said species. The present communication embodies the results of those two studies.

\section{Materials and Methods}

The mite species Tetranychus hypogeae was collected for study of life cycle and bio-efficacy of green pesticides from Blood Beauty and Tajmahal varieties of roses in the flower garden of Ramakrishna Mission, Narendrapur.

\section{For studying life cycle the following techniques were followed}

- The mite infested leaves of the varieties mentioned were collected from the field, brought to the laboratory and about 10 females each were released on two excised leaves kept on wet cotton pad in a Petridish (10cm diameter) for allowing the females to lay eggs.

- Next morning, the excised leaves were examined under stereo-binocular microscope if the females had laid eggs on excised leaves. In case a total of 20-30 eggs were laid, the females were removed or killed, leaving only the eggs on excised leaves. All the eggs were counted and encircled with a gel pen for taking further observations.

- Observations were recorded at 24hours interval to see if the eggs had hatched.

- The freshly hatched larvae were transferred to excised leaves (one larva on each excised leaf, kept on wet cotton pad in Petridish). Each excised leaf was numbered and altogether 15 such excised leaves were taken to represent 15 replications to begin with the experiment. 
- Observations were recorded at 24 hours intervals till the larvae developed to the adult stage. Those larvae which died, the data pertaining to those were discarded from the experiment.

- Observations towards different developmental stages like larva, protonymph, deutonymph, adult, total developmental period (egg-adult) were recorded.

- In addition, the duration of other periods like preoviposition, oviposition, post-oviposition periods, sexratio, longevity, fecundity, etc. were also recorded following conventional methods.

- The necessary statistical analysis like mean \pm SE was calculated.

Methodology for studying bioassay for green pesticides

- The green pesticides as Neem Seed Karnel extract (both aqueous and alcoholic, each 5\%), Ramtulsi (Ocimum gratissimum) (5\%), Palash (Butea monosperma) (5\%), Parthenium (Parthenium hysterophorus) (5\%) were prepared along with control (with water spray).

- The plant extracts with different concentrations were prepared following methodologies of (Sarmah et al. 2009; Mech et al. 2015; Mamun \& Ahmed 2011) ${ }^{[15,9,7]}$.

- The application of green pesticides was done using a glass automizer through which a definite quantity of pesticidal fluid was sprayed topically on the test mite.

- Observations towards mortality were recorded at 24 hours interval till 96 hours.

- The mortality was calculated using the formula = Number of dead mites

$\frac{\text { Total number of mites }}{} \times 100$ (McDonald et al. 1970).

- The necessary statistical analysis was done.

\section{Results}

\section{Study on life cycle}

A perusal to Table-1 indicates the following-

\section{Mating and incubation period}

The male emerged before the emergence of female as the male did not pass through the deutonymph stage. The newly emerged female was ready for mating and during mating the male crawled underneath the female and curved its posterior portion in such a manner so that the aedeagus enters the female genital aperture. This process took about 1-2 minutes. The female once mated did not allow any further mating. The mated female started ovipositing a little after mating $(2.02 \pm$ 0.05 days). The egg period lasted for 3-5 days (mean $2.02 \pm 0.05$ days). The freshly laid eggs were glossy and colourless but gradually those assumed a reddish tinge. The larva emerged from the matured egg by splitting the egg-shell.

\section{Larva}

The larval period was for $1-2$ days $(1.18 \pm 0.31$ days $)$. It was hexapod. It was very sluggish and did not feed. The freshly emerged larva was creamish and later turned light reddish. It moulted to protonymph.

\section{Protonymph}

The protonymph period lasted for 1-2 days (1.18 \pm 0.31 days). It was octopod and was more agile than larva but was a slow feeder. After completion of protonymphal period it moulted to the deutonymph stage. In case of male, the protonymph directly moulted into adult male.

\section{Deutonymph}

The deutonymph was much more active than protonymph. It was reddish and voracious feeder. This period lasted for 2-3 days $(1.91 \pm 0.06$ days). After which it moulted to the adult stage.

Life Cycle: The life cycle took 9-14 days (11.20 \pm 1.15 days) to reach from eggs to adult stage.

\section{Adult and preoviposition period}

The adult female was brightly reddish, very active, good feeder and started laying eggs. 1-2 days (1.18 \pm 0.31 days) after emergence and that was its preoviposition period.

Oviposition period: The oviposition period lasted for $8-16$ days (10.09 \pm 0.15 days). The eggs were laid scatteredly.

Post oviposition period: This period ranged between 1-2 days $(1.25 \pm 0.16$ days).

Fecundity: $18-50$ eggs $(34.00 \pm 1.15$ eggs $)$ in the life-time of female.

Longevity: Female lived for 10-16 days (12.12 \pm 1.15 days) while a male had a shorter longevity of $1.82 \pm 1.16$ days.

Sex ratio: The male:female sex ratio was found to be 1:3.

Table 1: Life cycle of Tetranychus hypogaea Gupta on rose under laboratory condition

\begin{tabular}{|c|c|c|c|}
\hline $\begin{array}{c}\text { Serial } \\
\text { number }\end{array}$ & Life cycle stages & $\begin{array}{c}\text { Range of Duration } \\
\text { in days }\end{array}$ & Mean $\pm($ SE) \\
\hline 1. & Incubation & $3-5$ days & $2.02 \pm 0.05$ \\
\hline 2. & Larva & $1-2$ days & $1.18 \pm 0.31$ \\
\hline 3. & Protonymph & $1-2$ days & $1.18 \pm 0.31$ \\
\hline 4. & Deutonymph & $2-3$ days & $1.91 \pm 0.06$ \\
\hline 5. & Egg to adult & $9-14$ days & $11.20 \pm 1.15$ \\
\hline 6. & Pre-oviposition & $1-2$ days & $1.18 \pm 0.31$ \\
\hline 7. & oviposition & $8-16$ days & $12.02 \pm 0.15$ \\
\hline 8. & Post-oviposition & $1-4$ days & $1.25 \pm 0.16$ \\
\hline 9. & Fecundity & $28-40$ eggs & $34.00 \pm 1.15$ \\
\hline 10. & Female longevity & $10-16$ days & $12.12 \pm 1.15$ \\
\hline 11. & Male longevity & $3-5$ days & $1.82 \pm 1.16$ \\
\hline 12. & $\begin{array}{c}\text { Sex ratio (male : } \\
\text { female) }\end{array}$ & $1: 3$ & \\
\hline & \multicolumn{3}{|l}{} \\
\hline
\end{tabular}

\section{Study on bioefficacy on green pesticides}

A perusal to Table-2 giving mortality data of Tetranychus hypogeae at different intervals after spraying indicated the mortality as below-

24 hours: At 24 hours, the percentage mortality was maximum in case of Parthenium at 5\% concentration which was 66.05 and it was at par with alcoholic extract of NSKE where the percentage mortality was 61.88 . Both the mortalities were superior to the other treatments. Palash leaf extract 5\% and Lantana camara leaf extract 5\% were at par being $53.14 \%$ and both were superior to Ramtulsi (5\%) leaf extract $(39.58 \%)$ and aqueous extract of Neem Seed Karnel $(5 \%)(24.72 \%)$. The latter was inferior to the former. No mortality was recorded in case of control.

48 hours: In all the treatments, the percentage mortality increased with increase of time interval. The maximum mortality was in case of Parthenium 5\% (86.94\%) and that 
was at par with Lantana leaf extract 5\% (83.98\%) and NSKE alcoholic extract 5\% (82.82\%). All these three were superior to the other treatments. The percentage mortality in case of Palash was $79.15 \%$. NSKE aqueous extracts was inferior to all treatments (25\% mortality). No mortality was recorded in case of control.

72 hours: The mortality at this interval registered further increase of $92.26 \%$ in case of Parthenium 5\% extract but that was at par with Lantana $5 \%$ extract $(91.53 \%)$ and alcoholic extract of NSKE (89.38\%) and Palash 5\% (88.23\%). All were superior to Ramtulsi 5\% where the percentage mortality was $81.22 \%$ and it was superior to NSKE aqueous extract where it was $49.47 \%$. No mortality was recorded in case of control.

96 hours: The Parthenium and Lantana leaf extracts both registered $100 \%$ mortality, being at par with alcoholic NSKE extract but superior to the other treatments. The NSKE aqueous extract was poorest among all $(52.16 \%)$ and was inferior to Ramtulsi 5\% extract $(86.31 \%)$. Control treatment registered no mortality.

Mean mortality: The percentage of mean mortality achieved in different treatments may be arranged in the following descending order Parthenium 5\% (86.31\%) > Lantana 5\% $(82.04 \%)>$ NSKE alcoholic extract $(81.68)>$ Palash $5 \%$ $(77.68 \%)>$ NSKE aqueous extract $(37.86 \%)$. Among these, the percentage mortality in case of Parthenium, Lantana, NSKE was at par having no significant difference among themselves. But the Palash leaf extract 5\% (77.68\%) was superior to Ramtulsi leaf extract $5 \%$ and the latter was superior to NSKE aqueous extract.

Table 2: Percentage mortality of Tetranychus hypogeae Gupta on rose at different intervals after spraying green pesticides

\begin{tabular}{|c|c|c|c|c|c|c|}
\hline Sl. no. & Statements & 24hours & 48hours & 72 hours & 96 hours & $\begin{array}{c}\text { Mean } \\
\text { mortality }\end{array}$ \\
\hline 1. & $\begin{array}{c}\text { Neem Seed Kernel Extract (NSKE) } \\
\text { aqueous extract 5\% }\end{array}$ & $24.72(30.59)$ & $\begin{array}{c}25.00 \\
(31.17)\end{array}$ & $\begin{array}{c}49.47 \\
(45.27)\end{array}$ & $\begin{array}{c}52.16 \\
(46.79)\end{array}$ & $37.86(38.45)$ \\
\hline 2. & $\begin{array}{c}\text { Neem Seed Kernel Extract (NSKE) } \\
\text { alcoholic extract 5\% }\end{array}$ & $61.88(52.11)$ & $\begin{array}{c}82.82 \\
(69.73)\end{array}$ & $\begin{array}{c}89.38 \\
(74.35)\end{array}$ & $\begin{array}{c}92.65 \\
(74.30)\end{array}$ & $81.68(67.62)$ \\
\hline 3. & Ramtulsi (Ocimum gratissimum) & $39.58(38.34)$ & $\begin{array}{c}60.37 \\
(51.02)\end{array}$ & $\begin{array}{c}81.22 \\
(64.57)\end{array}$ & $\begin{array}{c}86.31 \\
(70.01)\end{array}$ & $66.87(35.98)$ \\
\hline 4. & Palash (Butea monosperma) 5\% & $53.14(46.82)$ & $\begin{array}{c}79.15 \\
(63.57)\end{array}$ & $\begin{array}{c}88.23 \\
(73.09)\end{array}$ & $\begin{array}{c}90.20 \\
(72.38)\end{array}$ & $77.68(63.89)$ \\
\hline 5. & Parthenium (Parthenium & $66.05(54.92)$ & $\begin{array}{c}86.94 \\
(72.16)\end{array}$ & $\begin{array}{c}92.26 \\
(82.61)\end{array}$ & $\begin{array}{c}100.00 \\
(90.00)\end{array}$ & $86.31(74.92)$ \\
\hline 6. & hysterophorus) 5\% & $53.14(48.82)$ & $\begin{array}{c}83.48 \\
(70.18)\end{array}$ & $\begin{array}{c}91.53 \\
(76.16)\end{array}$ & $\begin{array}{c}100.00 \\
(90.00)\end{array}$ & $82.04(71.29)$ \\
\hline 7. & Lantana camara 5\% & 0.00 & 0.00 & 0.00 & 0.00 & 0.00 \\
\hline 8. & Critical Difference at 5\% level & 9.82 & 6.16 & 9.91 & 8.79 & 8.67 \\
\hline 9. & Standard Error Mean (SEM) \pm SE & 1.30 & 1.53 & 3.11 & 1.77 & 1.93 \\
\hline
\end{tabular}

*Note: The figures in parenthesis are angular transform values

\section{Conclusion}

From the mortality data given above, the following conclusion can be drawn-

- All the green pesticides proved toxic to the mite (Tetranychus hypogeae) though the percentage mortality varied.

- The extracts of Parthenium, Lantana and alcoholic extract of NSKE were better than other treatments.

- Ramtulsi and Palash extracts also were reasonably good.

- The aqueous extract of NSKE was poorest among all.

- Any of the treatments excepting the aqueous extract of NSKE may be attempted for control of this mite.

\section{Discussion}

\section{Study on life cycle}

The life cycle of this mite has not been studied earlier and hence the data collected in the present study could not be compared with those of others. However, reviewing the results of some earlier studies on other species of Tetranychus, like Gomes et al. (2017) on T. neocaledonicus, Kaur \& Zalom (2017) on T. urticae, Mondal \& Gupta (2017) on $T$. sayedi, it appeared that T. hypogeae completed its life cycle in a shorter time and duration of different developmental periods was also shorter. However, egg- adult and fecundity followed those reports cited above.

Muralidharan (2006) reported that $O$. coffeae completed life cycle in 21-25 days which was too high as comparted to 9-14 days as observed here. The duration of deutonymphal period was $2.20 \pm 0.20$ days in $O$. coffeae (Saha, 1997) and the present result is very close to that. The fecundity in case of $O$. coffeae was 68.07 \pm 3 eggs (Das \& Das 1967) which is much higher as compared to observations made in the present study.

\section{Study on bio-efficacy on green pesticides}

Many of the plant extracts contained complex mixture of monoterpenes, biogenetically related phenols and sesquiterpenes which show toxic effect (Isman, 2006) and therefore the plant extracts tested in the present study fell in line with that. Radhakrishnan (2010) and Mech et al. (2015) ${ }^{[9]}$ got good control of tea mite $O$. coffeae with NSKE 5\% extract and the present result tallied with that. Samrah et al. (2009) who tested Lantana camara extract on O.coffeae also got good mite control as has been observed in the present study. Rincon et al. (2012) studied efficacy of botanicals against mites and the present report also agreed with that recording $100 \%$ mortality at 96 hours interval.

\section{Acknowledgements}

The authors offer sincere thanks to Swami Sarvalokananda and Swami Vasavananda, the Secretary and Assistant Secretary, respectively of Ramakrishna Mission Ashrama, Narendrapur, for providing infrastructure facilities and encouragements.

\section{References}

1. Das GM, Das SC. Effect of temperature and humidity on 
the development of tea red spider mite, Oligonychus coffeae (Nietner). Bulletin of Entomological Research 1967;57(3):433-6.

2. Gomes Neto AV, Silva PR, Melo JW, Melo Júnior LC, França SM. Biology and life table of Tetranychus neocaledonicus on lima bean. International journal of acarology 2017;43(8):622-6.

3. Gupta SK, Gupta YN. A Taxonomic Review of Indian Tetranychidae (Acari: Prostigmata): With Descriptions of New Species, Re-descriptions of Known Species, and Keys to Genera and Species. Mem. Zool. Surv. India 1994;18(1):1-196.

4. Gupta SK. Contribution to our knowledge of tetranychid mites (Acarina) with descriptions of three new species from India. Oriental Insects 1976;10(3):327-51.

5. Isman MB. Botanical insecticides, deterrents, and repellents in modern agriculture and an increasingly regulated world. Annu. Rev. Entomol 2006;51:45-66.

6. Kaur P, Kaur P, Zalom FG. Effect of temperature on the development of Tetranychus urticae and Eotetranychus lewisi on strawberry. Journal of Entomology and Zoology Studies 2017;5(4):441-4.

7. Mamun MS, Ahmed M. Prospect of indigenous plant extracts in tea pest management. International Journal of Agricultural Research, Innovation and Technology 2011;1(2355-2020-1485):16-23.

8. McDonald LL, Guy RH, Speirs RD. Preliminary evaluation of new candidate materials as toxicants, repellents, and attractants against stored-product insects (No. 882). US Agricultural Research Service 1970.

9. Mech J, Deka P, Bhuyan P, Bhattacharyya R. Acaricidal activities of Parthenium hysterophorus L. against Red Spider Mite, Oligonychus coffeae Nietner (Acarina: Tetranychidae) of Tea. International Journal of Science and Research 2015;4(5):901-904.

10. Mondal S, Gupta SK. Life cycle of a plant parasitic mite, Tetranychus sayedi Baker \& Pitchard (Acari: Tetranychidae) on two hosts from West Bengal, India. Journal of Parasitic Diseases 2017;41(3):862-8.

11. Muraleedharan N. Sustainable cultivation of tea. Handbook of tea culture, UPASI Tea Research Foundation, Niren Dam, Valparai 2006;24:1-12.

12. Radhakrishnan B. Indigenous botanicals preparations for pest and disease control in tea. Bull. UPASI Tea Res. Found 2010;55:31-9.

13. Rincón RA, Rodríguez D, Coy-Barrera E. Botanicals against Tetranychus urticae Koch under laboratory conditions: A survey of alternatives for controlling pest mites. Plants 2019;8(8):272.

14. Saha K. Bionomics of plant feeding mites of Tea with special reference to their natural enemies (Doctoral dissertation, Department of Agricultural Entomology, Bidhan Chandra Krishi Viswavidyalaya, Mohanpur, West Bengal, INDIA, Pin-741252);1997.

15. Sarmah M, Rahman A, Phukan AK, Gurusubramanian G. Effect of aqueous plant extracts on tea red spider mite, Oligonychus coffeae, Nietner (Tetranychidae: Acarina) and Stethorus gilvifrons Mulsant. African Journal of Biotechnology 2009;8(3).

16. Sarmah M. Bioefficacy of neem kernel aqueous extract (NKAE) against tea red spider mite, Oligonychus coffeae, Nietner and its effect on Stethorus gilvifrons Mulsant, a potential predator of red spider mite. Journal of Biopesticides 2016;9(2):204. 